\title{
MODOS DE VIDA DE INTERNOS DO SISTEMA PENITENCIÁRIO CAPIXABA
}

\author{
Gilead Marchezi Tavares \\ Paulo Rogério Meira Menandro \\ Universidade Federal do Espírito Santo, Vitória, Brasil
}

\begin{abstract}
RESUMO: Partindo do referencial da RedSig e da filosofia espinosana, este trabalho objetivou investigar os modos de vida produzidos na e pela prisão, apostando no conhecimento de alguns circunscritores do processo de constituição de pessoas que habitam os presídios. Foram realizadas duas entrevistas com quatro internos do Instituto de Readaptação Social de Vila Velha (ES), com um período de espaçamento de um ano entre elas. A análise das entrevistas seguiu no aporte metodológico das Práticas Discursivas como produção de sentidos, implicando adotar postura construcionista e ressignificar a relação entre sujeito e objeto para fora da idéia cristalizada de dualidade. Os quatro casos investigados são apresentados a partir da iluminação das histórias de vida dos sujeitos entrevistados, de seus sentimentos em relação à experiência da vida prisional e de seus modos de vida.
\end{abstract}

PALAVRAS-CHAVE: presídios; presidiários; modos de vida; circunscritores.

\section{WAYS OF LIFE OF INTERNS OF ESPÍRITO SANTO STATE PENITENTIARY SYSTEM}

ABSTRACT: Stemming from the RedSig referential and Spinozian philosophy, this work had as objective to investigate ways of life produced in and by the prison, anchored on the knowledge of some constraints of the process of constitution of people who live in prisons. Two interviews with four interns of Instituto de Readaptação Social (Social Readaptation Institute) of Vila Velha (Espírito Santo State, Brazil), were performed, one year apart. The analysis of the interviews proceeded on the methodological approach of Discursive Practices as production of meaning, implying the adoption of a constructionist posture and re-signification of the relation between subject and object outside the crystallized idea of duality. The four investigated cases are presented after the highlight of the life histories of the interviewed subjects, of their feelings towards prison life experience and their ways of life.

KEY WORDS: prisons, inmates, ways of life, constraints.

A penitenciária e a pena de reclusão têm sido alvos de constantes discussões nos últimos anos, sobretudo no tocante à superpopulação e à ineficiência, que se apresentam como problemas aparentemente insolúveis, tal sua longevidade. A indignação jornalística e popular freqüentemente gira em torno das rebeliões e das fugas, ocasiões nas quais sempre se discute o absurdo número de criminosos distribuído no sistema carcerário brasileiro e a eventual possibilidade da instauração da pena de morte.

Os meios de comunicação apresentam à população o risco ao qual está sujeita, emanado do sistema prisional, uma vez que ele não cumpre eficazmente seu desejado papel de formar um cordão de isolamento em torno das "anomalias" sociais. Em consonância, o que se espera das autoridades responsáveis é que ponham em funcionamento um conjunto de estabelecimentos carcerários com dispositivos físicos, materiais e recursos humanos suficientes para calar ou tornar invisível a massa carcerária. $\mathrm{E}$ isso deve ser feito consumindo o mínimo possível de verba pública. Tal perspectiva foi apresentada por Thompson (1976) quando aponta que o fato de um ex-presidiário tornar a cometer atos criminosos é, em geral, visto com naturalidade, pois da prisão exige-se, apenas, que mantenha seus internos longe da sociedade. Acrescentaríamos que o fato mencionado talvez seja visto até com certa satisfação, já que reforça a percepção compartilhada por muitas pessoas de que nada há a fazer com "bandidos" a não ser mantê-los trancafiados (sem muita preocupação com as condições em que o encarceramento se dará) ou exterminá-los.

Debord (1997), apresentando a idéia de "sociedade do espetáculo", afirma que as informações divulgadas pela mídia operam de forma a impossibilitar a sua contestação pelo conhecimento cotidiano. A crença quase que absoluta no conhecimento "especializado", detentor da verdade, que, por sua vez, trabalha produzindo e reproduzindo a idéia de ignorância popular, auxilia no processo de aceitação tácita de informações advindas dos 
meios de comunicação de massa. Com os mecanismos globais "espetaculares" de divulgação de acontecimentos de qualquer parte do mundo, tal sociedade, ao mesmo tempo em que suprime a distância geográfica, recolhe interiormente a distância entre as pessoas, operando uma separação que pode ser entendida como sendo os processos de exclusão social.

Focalizando a pena de privação de liberdade e considerando a problemática da instituição carcerária emergente no contexto atual como questão social, política e econômica, o presente trabalho interessou-se em analisar possíveis "rotas de fuga" dos modos de vida encarcerada que abortassem as concepções e práticas prisionais produtoras da idéia de uma identidade de presidiário ou de criminoso.

Tendo em vista a precariedade de recursos e projetos, a insalubridade do ambiente físico e a violência notória dos estabelecimentos penais brasileiros, partimos do princípio de que a "recuperação" do apenado é retórica em desuso nos discursos políticos, jurídicos e midiáticos brasileiros.

\section{Modos de Vida e Constituição de Sujeitos}

O presente trabalho teve como objetivo investigar os modos vida produzidos na e pela prisão. Apostamos no conhecimento, desse modo, de alguns circunscritores do processo de constituição de pessoas que habitam as instituições presidiárias.

Acreditamos que o esclarecimento trazido por Rossetti-Ferreira, Amorim, Silva e Carvalho (2004), nos estudos da Rede de Significações (RedSig), acerca do conceito do termo pessoa (apoiado em Sampson, 1993) ajuda-nos a apresentar as concepções de sujeito e subjetividade que utilizamos para análise do corpus de pesquisa. "O ser humano é relação, constrói-se na relação com o outro e com o mundo e só se diferencia e se assemelha no espaço relacional" (Rossetti-Ferreira, Amorim, Silva, \& Carvalho, 2004, p. 25).

Rompendo com a unidade e a indivisibilidade do indivíduo centrado em si mesmo e com a idéia de traços comportamentais inerentes ao ser, relativos à personalidade e ao self, falar de sujeito e de subjetividade requer, primeiramente, a desconstrução de dicotomias antigas e talvez ultrapassadas do discurso psicológico: indivíduo e ambiente, individual e social, subjetividade e objetividade.

Dos soviéticos Vygotsky e Leontiev trazemos a compreensão de que não há universalidade em relação à construção do ser humano no que diz respeito à subjetividade, constituída que seria a partir da inserção no mundo da cultura e da linguagem. Acreditando que a mente humana é a cultura internalizada que daria origem a processos cognitivos superiores, Vygotsky (1991) dá um grande passo em direção à construção da idéia de um homem que só existe imerso nas relações sociais que, por sua vez, traduzem sempre um momento histórico particular e dinâmico. Dizemos um passo porque a psicologia soviética, por meio da dialética e da idéia de coconstrução dos pólos subjetividade versus objetividade, manteve a dualidade e a dissociação entre o sujeito e a realidade. Todavia, entendemos que os elementos fundantes da psicologia sócio-histórica, as categorias de análise do psiquismo humano, possibilitam a percepção da não linearidade ou não regularidade na constituição dos sujeitos e de suas trajetórias de vida.

Nesse sentido, a apreensão dos contextos cultural e socialmente regulados se coloca de suma importância para a compreensão dos processos de desenvolvimento do ser humano e, assim, da constituição do sujeito. No nosso caso, especificamente, para conhecermos os sujeitos que habitam os presídios, precisaríamos conhecer que mundo globalizado é esse em que vivemos, incluindo aí aspectos políticos e econômicos. Mais do que isso, seria necessário que elucidássemos aspectos físicos, materiais e funcionais dos presídios. Tendo em vista que os contextos não existem isoladamente das pessoas que os compõem, faz-se premente, ainda, conhecer os campos interativos dialógicos (Rossetti-Ferreira et al., 2004) dos internos do sistema carcerário, que seja, os outros com os quais estabeleceram suas primeiras interações e também as demais ao longo de suas vidas. Tudo isso mergulhado e impregnado numa matriz sócio-histórica, de natureza semiótica, constituída e constituinte de elementos discursivos, afetivos, sócio-econômicos, políticos, históricos e culturais que se entrelaçam, interagindo e se desenvolvendo a todo o tempo.

A RedSig, considerada ferramenta teóricometodológica para a compreensão dos processos de desenvolvimento (diríamos, ainda, dos processos de constituição dos sujeitos), envolve, desse modo, os contextos, os campos interativos, as dimensões temporais, as pessoas e, ainda, a matriz sócio-histórica, manancial semiótico do devir humano. Tais elementos são circunscritores, acessíveis ao nosso conhecimento, dos processos de desenvolvimento, dos processos de constituição dos sujeitos e, consequientemente, dos processos de construção dos modos de vida.

Seguindo a linha de raciocínio, podemos considerar que os modos de vida, ou seja, as formas singulares de agir no mundo e de perceber, sentir e pensar o mundo e a si mesmo, são produzidas nas relações entre seres constituídos biologicamente em um corpo que sente e que é afetado por todos aqueles circunscritores. Assim, os modos de vida se constituem, a todo o momento, nas relações - configuradas como RedSig. Dessa forma, modo Contrapondo-nos à psicologia de herança platônica, que se mantém na dicotomia corpo-mente, apoiamo-nos em 
Espinosa (1973) para trazer à luz a compreensão de corpo e de mente como expressões de uma mesma realidade, uma só e mesma coisa expressa de duas maneiras diferentes. Espinosa é um monista que faz uma ontologia bimembre. Em sua obra, a mente humana é entendida como força pensante, como atividade pensante que se realiza como percepção, imaginação, razão, vontade, reflexão etc., tudo entendido como uma idéia. A mente, então, como potência pensante, é uma idéia que tem idéias (conteúdos pensados por ela) sempre voltadas para os objetos que constituem seus conteúdos ou suas significações. Sendo o corpo o primeiro objeto a constituir a atividade pensante, pode-se concluir que a mente é uma idéia do corpo, ou seja, ela está no corpo e dele deriva. $\mathrm{O}$ corpo é objeto extremamente complexo e diverso, por isso e através disso é apto a afetar e ser afetado por corpos exteriores a partir das interações, o que resulta em afecções ${ }^{1}$ (Gleizer, 2005). Termo utilizado por Espinosa para explicar as modificações causadas no corpo a partir das interações com outros corpos, afecção auxilia na compreensão dos "encontros" que travamos em nossa existência que operam mudanças de curso ou manutenção do percurso trilhado. Pressupondo uma intercorporeidade originária, Espinosa afirma que somos compostos ao infinito de partes extensivas exteriores umas às outras. Tais partes compõem cada corpo sob determinadas relações que configuram sua organização como um grau de potência, o que caracteriza sua essência singular, cabendo ainda a compreensão de potência como "capacidade de afetar outros corpos e de ser por eles afetado sem se destruir, regenerando-se com eles e os regenerando" (Chauí, 2006, p. 52a). Assim, o corpo é biológico, mas também é social, emocional, simbólico. "Unidos, corpo e mente constituem um ser humano como singularidade afetiva e individualidade complexa em relação contínua com todos os outros. A intersubjetividade é, portanto, originária" (Chauí, 2006, p. 52b).

Tais considerações ajudam-nos a dissolver dicotomias e considerações deterministas infrutíferas do ponto de vista metodológico e prático, uma vez que a determinação dos fenômenos deve ser apreendida não como decorrência de uma variável, mas de uma infinidade de elementos materiais e simbólicos e que, portanto, não se configura como dado previsível. A Rede de Significações está aí colocada como a causa e a consequiência dos fenômenos humanos, ou seja, não opera por causalidade e sim por acoplamento entre processos ou fluxos heterogêneos.

Seguindo no aporte filosófico espinosano, que nega o "presente venenoso" da filosofia de herança platônica, a transcendência, entende-se que a essência do humano implica em sua existência e que, portanto, sua potência, com estatuto de relação, é a capacidade humana para ser, para agir, para perseverar no seu ser, para ter mais força de realidade, enfim, de existência. Assim, podemos com- preender os caminhos múltiplos e alternativos do desenvolvimento humano e a partir daí investigar aquilo que aumenta ou que diminui a potência do ser.

Acreditamos que a concepção de circunscritores presente no referencial da RedSig nos auxilia na investigação dos modos de vida. De ordem material e simbólica, impregnando a organização dos ambientes e os padrões de relacionamento culturalmente estabelecidos, os circunscritores seriam "fatores que simultaneamente compelem ao e limitam o desenvolvimento humano" (RossettiFerreira et al., 2004, p. 81). Propomos o entendimento de tais fatores como os "encontros" dos corpos que colocam em operação a produção necessária de vida, a preservação da vida. Por isso, compelem ao desenvolvimento e o limita apenas no sentido de se operar na relação necessária de manutenção da vida ou da composição de sua organização. É através destes fatores, constituintes da RedSig, que o sujeito caminha e trilha trajetórias diversas e, às vezes, descontínuas².

\section{O Encontro com Internos do Sistema Penitenciário Capixaba}

Conhecendo as dificuldades relacionadas ao contato com os detentos e à inserção no âmbito do espaço em que vivem, o primeiro passo seguido foi o contato direto com a Secretaria de Justiça do Estado do Espírito Santo (SEJUS), responsável pelas penitenciárias do Estado. A visita à SEJUS rendeu-nos autorização e apoio para realizarmos as entrevistas no Instituto de Readaptação Social (IRS) de Vila Velha "Professor Jair Etienne Dessaune", a penitenciária de regime fechado da Grande Vitória.

O IRS foi fundado em 1924 e possui 193 celas (aproximadamente 165 individuais). Em maio de 2001, a penitenciária continha 210 internos. Após a intervenção da Polícia Militar nos presídios do Estado, ocorrida em fevereiro de 1999 , foram criadas as frentes de trabalho que privilegiaram cerca de $80 \%$ dos internos, em geral, aqueles que têm vínculos familiares ativos e envolvimento religioso.

\section{A Entrada no IRS}

Com o aval da SEJUS, dirigimo-nos ao Complexo Penitenciário de Vila Velha onde ficam a Casa de Detenção, o Anexo (também conhecido como Casa de Passagem) e o IRS. Este é o último estabelecimento do "condomínio fechado".

O Complexo tem uma localização bastante interessante. Situa-se no Bairro da Glória, em Vila Velha, em uma região parecida com uma península. Desse modo, no canal que dá acesso à porção de terra cercada pela baía de Vitória e pelo rio Aribiri há um grande portal que indica o início do Complexo. Nesse portal encontram-se policiais militares armados que regulam e fiscalizam a 
entrada e a saída do Complexo. A estrada interna do Complexo que nos leva até o IRS é calçada com paralelepípedos e deve ter aproximadamente dois quilômetros. Ao longo da estrada existem postos policiais de vigília - mirantes erguidos em estruturas de metal - e homens fazendo a capina das margens da "península" onde há plantações. A vista da baía e da cidade de Vitória faz-nos esquecer por alguns instantes as propriedades do local. Chegando ao IRS, passamos pela oficina de estofamentos, por um lava-jato improvisado, pelas grades que separam o lado interno da penitenciária e, finalmente, por uma espécie de beco que leva ao setor administrativo da instituição. O IRS tem semelhança com um forte do século XVIII: muros altos, estrutura pesada de paredes largas, localizado na ponta da península, com uma vista fantástica da baía e da cidade de Vitória.

A penitenciária é constituída de cinco pavilhões ou alas e possuía, à época da pesquisa, 15 frentes de trabalho: fábrica de blocos, marcenaria, capotaria, lava-jato, fábrica de sofás, oficina mecânica, granja, pocilga, horta, plantação de pimenta, capina, faxina interna, faxina da administração, refeitório e assentamento. Destes, somente a capina não era remunerada. $\mathrm{O}$ iniciante deve começar pela capina e depois "progredir" gradativamente. A divisão dos internos nas alas não se deve ao tipo de crime cometido, e sim ao perfil do interno, que é avaliado pela Assistente Social.

A coleta durou um ano e meio. Tratou-se de, num primeiro momento, entrevistar presidiários recém-chegados à Instituição, advindos de outros presídios, nos quais não há trabalho, e após a passagem de aproximadamente um ano, entrevistá-los novamente, para averiguar uma possível transformação ocorrida como consequiência do trabalho ou da passagem por uma Instituição com características diferentes dos presídios em que não há qualquer possibilidade de remição da pena através do trabalho.

Desse modo, foram realizadas duas entrevistas orientadas com quatro internos do IRS, focalizando a atenção sobre os seus modos de vida no cárcere e as suas percepções sobre a trajetória de vida trilhada até a entrada na prisão. Em tempo, esclarecemos que as entrevistas foram consentidas voluntariamente após a explicação dos objetivos da pesquisa e da utilização de gravador de voz, tendo sido, dessa forma, assinado por cada um dos participantes um termo de consentimento informado. Todos os nomes de participantes mencionados na apresentação dos resultados são fictícios.

Durante a passagem de um ano, consideramos importante manter as visitas semanais à instituição, garantindo a vivência da pesquisadora na situação pesquisada. A vivência e a descrição em um "diário de campo" de tudo o que acontece na situação pesquisada, registrando de modo sistemático quem, quando, onde, como as ocorrências se dão, sem perder de vista o obje- to de estudo e as perguntas específicas elaboradas a priori, favorecem o que os propositores da RedSig chamam de "mergulho" do pesquisador na situação, "que lhe permita apreender os vários elementos envolvidos, propiciando-lhe uma visão panorâmica e um primeiro delineamento dos significados e sentidos na situação investigada" (Rossetti-Ferreira et al., 2004, p. 31).

Costumeiramente, a instituição mostrava-se um poço de tranqüilidade e lentidão. $\mathrm{O}$ tempo parecia ser infinito para as pessoas da instituição. Um dia, um dos internos da faxina, esfregando o chão, percebendo a ansiedade da pesquisadora em resolver o que havia ido fazer lá, disse sem parar de trabalhar: "Aqui nós temos todo o tempo do mundo, doutora".

\section{A Análise}

Com a coleta pronta e a construção do corpus de pesquisa, começamos a análise de conteúdo pelo quadro de referências, na tentativa de visualizarmos as regularidades de idéias e sentidos que nos possibilitassem a elaboração das tradicionais categorias de análise. Foi, então, que precisamos o risco imposto pela pesquisa social qualitativa ou, mais precisamente, pela pesquisa construcionista (Spink \& Frezza, 2004). Se, por um lado, a implicação política com o universo a ser pesquisado constitui condição para a pesquisa social, por outro, tal ocupação de lugar fatídico oferece o risco de nos metamorfosear no universo pesquisado, produzindo uma paralisia cognitiva que nos impede de realizar a análise. Não é para menos, na medida em que me vejo naquilo que chamamos em metodologia científica de dados - recorte da realidade objetiva que deveria se encontrar fora de nós - que precisam ser codificados e decodificados, se possível através de quantificação, e exatamente por isso requer algum distanciamento do pesquisador, compreendemos a inércia de pensamento num primeiro momento. Entendemos que se colocar novamente na posição de investigador da realidade, para assim produzir conhecimentos acerca dos fenômenos sociais, é ser capaz de colocar seus próprios afetos no jogo de dados. É reconhecer onde e como a realidade nos afeta, para assim ocuparmos um lugar político do qual podemos falar, sem ficarmos aprisionados na rede de afetos que nos compõe a todo o momento. Tal empreendimento tornou-se possível a partir do auxílio das propostas metodológicas da RedSig e das Práticas Discursivas.

Entender as entrevistas como práticas discursivas, ou seja, como interação, processo, produção de sentidos diversos no diálogo entre tantas vozes materializadas ali na pesquisadora e no participante, implicou adotar uma postura construcionista, ressignificando a relação entre sujeito e objeto para fora da idéia cristalizada de dualidade (Spink \& Menegon, 2004). 
A interpretação, como produção de sentidos, iniciou-se a partir da leitura da literatura sobre o tema e da coleta de dados, e a sua sistematização, necessária ao rigor científico, seguiu a linha narrativa presente nos blocos de investigação propostos. As respostas às perguntas da entrevista orientada foram pensadas como processos resultantes de territórios existenciais habitados pelo entrevistado e pela entrevistadora na situação da pesquisa (Spink \& Menegon, 2004).

\section{Valter, Jésus, Juvêncio e José: Singularidades e Massificações nas Produções de Modos de Vida}

\section{Valter e o Sentimento de Fracasso Produzido pelo Encarceramento}

Valter tinha 40 anos à época da entrevista e falava sobre o ano que se passou como época em que nada fez no presídio. Solicitou várias vezes ao setor de serviço social a participação em frentes de trabalho, mas não obteve êxito em nenhuma das vezes.

A freqüência à "escola" foi o que mudou a rotina de Valter nos últimos dias. Desse modo, a escola nos pareceu um importante circunscritor do processo de encarceramento de Valter, apreendido na produção de sentidos. Ele disse que estava aprendendo com a professora equação matemática e "alguma coisa de literatura". Com entusiasmo falou do curso de literatura ministrado por um professor chileno da faculdade que andou trabalhando por um tempo na escola do IRS.

A "escola" no IRS existe há algum tempo e se resume a uma pequenina sala insalubre (como todo o espaço físico interno do presídio), situada próxima à entrada da parte interna do presídio, com poucas carteiras estudantis velhas e uma estante de ferro com livros, revistas e jornais usados. A iniciativa foi de uma professora que presta o serviço uma vez por semana na qualidade de voluntária.

Projeto importante de transformação dos sujeitos e constituição de novos e diferentes modos de vida para além do presídio, através da abertura de oportunidades futuras, a escola, não só para atualização e aperfeiçoamento de saberes, mas também como possibilidade de alfabetização, e o curso de informática, como forma de inclusão digital e preparação para alternativas de trabalho no futuro, deveriam estar na ordem do dia em instituições carcerárias. Infelizmente, o que vimos foi uma oferta precária de tais iniciativas, além de serem pautadas em manifestações voluntárias e não em forma de projeto institucional oriundo de políticas públicas para o sistema carcerário.

O poder público e a imprensa há tempos se ocupam da falácia da construção de novos presídios mais seguros, preocupando-se com as fugas e a falta de espaço para depósito de novos presos pela polícia (sem se dar conta de que os novos presos em geral não são calouros do sistema). A reincidência não aparece como foco de atenção e fenômeno gerador de diretrizes políticas para a sua resolução. Nesse sentido, a preocupação com a transformação sócio-subjetiva do interno do sistema, através principalmente da educação, parece não estar colocada para o poder público, assim como não fundamenta a opinião pública sobre o tema dos presídios.

Neste sentido, a transformação do sujeito fica a cargo do tempo e do sofrimento, o que não muda as condições com as quais o sujeito chegou à instituição de precariedade de escolarização e de profissionalização, além de inexistir a evocada socialização ou ressocialização, cujo pilar poderia estar pautado na Educação.

É interessante tomar o fato de que Valter provém de uma família de classe média carioca e que teve oportunidades de freqüentar a escola e de sair de seu círculo social com um suporte sócio-econômico suficiente para recomeçar a vida em outra cidade na tentativa de se afastar do consumo de drogas ilícitas. Durante a entrevista, Valter sempre se mostra arrependido do trajeto feito na vida, suscitando a hipótese de que poderia ter tomado outros caminhos. Tal reflexão do entrevistado culmina com o sentimento de fracasso na vida, presente já na primeira entrevista. Não percebemos diferenças nos discursos da primeira e da segunda entrevista, mas sim uma continuidade de sofrimento marcado pela "consciência" de que teve tudo para escolher "bons" caminhos e preferiu o caminho "errado", por isso está pagando por tal escolha, o que o torna um fracassado na vida.

É o encarceramento que produz em Valter um modo de vida marcado pelo sentimento de fracasso. Olhar baixo, ombros caídos, postura de derrotado e choro contido. Valter atualiza processos de culpabilização pelo trajeto "escolhido", delimitando um território existencial.

Sei lá, eu acho que cada um traça o seu caminho, acho que meus pais queriam que eu estudasse, alguma coisa assim, fizesse um curso superior. A sociedade, acho que a sociedade não é culpada da gente estar aqui não, eu acho que o culpado de estar aqui sou eu mesmo. Foi um caminho que eu tracei, se eu quisesse eu teria ido por um outro caminho. Eu penso assim, né cara, no meu modo de vista, no meu caso, por exemplo, eu tive tudo, eu tive como estudar, eu tive uma família, eu tive o apoio dos meus pais e, portanto eu cheguei nessa e eu não culpo, no meu modo, eu não culpo nem a própria sociedade, que só estou nessa porque acho que eu procurei mesmo, eu que tracei esse caminho, senão a história poderia ter sido outra totalmente diferente ... Ah, eu me vejo como mais um que fraquejou na vida. Fracassei. 
Jésus e o Aprisionamento no Discurso Religioso

Jésus entrou na sala em que realizávamos as entrevistas carregando uma bíblia em baixo do braço. De cabeça baixa, olhando para o chão durante todo o tempo, Jésus comportava-se como se nunca houvesse conversado com a entrevistadora. Na tentativa de retomar num primeiro momento a primeira entrevista, relembramos a angústia expressada por Jésus por não conseguir, há um ano atrás, a tão sonhada liberdade condicional e a revolta contra o promotor que havia encampado o seu caso. Jésus respondeu, demonstrando-se conformado, que tinha ainda três anos para "pagar" de uma condicional que quebrou no ano de 1994.

O contato com a família se restringiu, nesse ano, às visitas de sua mulher. Afirmou que não fala com a mãe há algum tempo. De família muito pobre, Jésus não pode ter contato com a mãe, uma vez que ela não possui telefone, nem dispõe de dinheiro para a passagem de ônibus até o IRS. Jésus afirmou que a avó é quem se preocupa muito em visitá-lo, mas em função da idade de 70 anos fica mais difícil o deslocamento, além da dificuldade de obter autorização da instituição para a entrada. Porém, Jésus não se abala, afirmando que, apesar de tudo, "Deus está abençoando".

Ao ser questionado sobre o cotidiano durante este último ano no IRS, Jésus respondeu:

Agora eu sou evangélico e estou procurando mudar de vida, graças a Deus. 'Tô aí né, para que eu saia daqui transformado. Eu acredito que só Deus muda a nossa vida. O presídio não vai mudar não, mas Deus tem essa capacidade. Eu estou esperando... O que fez com que mudasse assim? O sofrimento. Aqui eu sofri demais, muito tempo sofrendo nessa vida e quando eu ouvi falar em Deus, falar dos caminhos dele... Realmente, foi o meu coração e tudo que os crentes falavam que mudou muito a vida e Deus vai mudar a minha também.

Mais uma vez é o sofrimento que aparece como agente transformador. Neste caso, não só o sofrimento de estar preso, mas sim o sofrimento de uma vida inteira de precariedades, de carências sócio-econômico-culturais, de frustrações em relação a anseios, comuns de um indivíduo nascido e criado em meio a muita pobreza, como assim já havia relatado na primeira entrevista. $\mathrm{Na}$ ausência de outras possibilidades de transformação da vida e no sentimento de impotência produzido pelo encarceramento, o encontro com um mundo religioso em que tudo se espera em um Outro, que é poderoso o suficiente para mudar aquilo que nós mesmos não conseguimos, é bastante compreensível.

Segato (2001), ao desenvolver projetos em presídios masculinos de Brasília, traz interessantes contribuições para o entendimento do engajamento religioso de presidiários. O trabalho da autora a permitiu perceber a existência de uma relação particular estabelecida pelos presidiários com a religião. De fato, a presença diária de religiosos nos presídios, que foi verificada também no IRS, atesta a relação estreita que internos desenvolvem com os discursos religiosos. Segato apresenta a idéia de que o discurso mais rico com o qual o detento tem contato é o discurso religioso, que lhe dá o direito à redenção, de se dizer bom, de princípios retos. Porém, tal discurso delimita as possibilidades do interno de modo a aprisioná-lo pela via do discurso. Ele estaria, assim, preso duas vezes, pela cadeia e pelo discurso. É lógica a conclusão de que o aprisionamento no discurso religioso auxilia a contenção da massa carcerária.

Jésus acredita que a conversão para o mundo religioso conferiu-lhe o respeito da administração do presídio (serviço social, chefe de disciplina, diretor, etc.) e também dos demais internos do IRS, o que o faz deixar de ser apenas mais um entre tantos presos. A construção e a assunção da identidade de servo de Deus, desta forma, o aproxima afetivamente dos demais irmãos da igreja, com quem agora vê semelhanças. Jésus afirma que, como servo de Deus, precisa ter amizade com todos para que possa aproximar-se e apresentar a palavra de Deus.

O encontro com Deus e o aniversário de 28 anos comemorado junto aos amigos na fé foram os eventos que marcaram o ano que se passou para Jésus. Vemos tais experiências como circunscritores do trajeto em curso de Jésus, encontros necessários à vida, mesmo que fundados em idéias inadequadas de redenção a partir de um "outro poderoso".

A investigação, na segunda entrevista, caminhou no sentido de entender como o sujeito compreende sua trajetória de vida até o cumprimento da pena em regime fechado e, mais uma vez, percebemos que a tendência, ao se ficar muito tempo no IRS, é se ver como o culpado e merecedor do castigo que se está sofrendo:

Muitas das vezes a gente quer arrumar até pretexto, quer culpar alguém, né? Eu creio que a gente mesmo é culpado disso tudo, porque existem dois caminhos, o caminho bom e o ruim, então a gente escolhe. Eu escolhi o errado e paguei pela minha escolha, eu paguei. Mas hoje Deus me alertou que o caminho que eu escolhi era errado, agora eu vou pelo caminho certo. Tenho que continuar pelo caminho certo, porque o caminho errado tem um fim pior do que esse ... se vou morrer, se vou ficar em uma cadeira de rodas, aleijado... Ele é a vida né? ... A salvação que Deus tem para nós. ... É a pessoas mesmo que escolhe, que escolheu o caminho errado, porque eu conheço muitas pessoas, muitos amigos meus que a mãe muitas vezes estava ausente, mas eles não deixaram de trabalhar, de estudar e não estão tão mal assim e eu aqui preso não estou tão mal porque Deus tem me confortado e é isso, a pessoa que escolhe, eu escolhi isso aí e estou pagan- 


\section{do por isso.}

O sofrimento e a culpa, enquanto modos de subjetivação, são efeitos de sujeitos passivos que desconhecem os processos sócio-históricos e éticos que os engendram. Aprisionados por estas paixões tristes ${ }^{4}$, os territórios existenciais tornam-se estanques, conferindo um ciclo viciado numa dinâmica produtora de passividade. No entanto, faz-se importante saber que se trata de uma política de dominação, ou, como queria Foucault (2002), um biopoder ${ }^{5}$ que se faz presente nas relações estabelecidas no Sistema Prisional.

\section{Juvêncio e o Não Arrependimento do Caminho Trilhado}

O início da segunda entrevista era o momento de retomar alguns dados da primeira como forma de confirmação, mas também como forma de aproximação maior com o entrevistado. Juvêncio parecia bastante à vontade na "conversa" com a entrevistadora relembrando a sua vida no interior, de onde veio e sua família de origem. Disse receber a visita da mulher e da filha de cinco anos todos os domingos, assim como acontecia há um ano atrás. A visita íntima do sábado não era possível porque a mulher é cabeleireira e não pode deixar de trabalhar aos sábados. A filha é a preciosidade de Juvêncio. Boa parte da entrevista foi dedicada a falar dela. Ao ser questionado acerca de como a menina lida com o fato de saber da condição de presidiário do pai, Juvêncio afirma que não pretende esconder nada da filha, pois ela é muito inteligente e um relacionamento de pai e filho não pode se basear na mentira. De vez em quando também recebe a visita de amigos de fora do presídio que considera como irmãos.

Um circunscritor importante do modo de vida criado por Juvêncio são as visitas, em especial de sua filha. O dia de visitas aumenta sua potência de vida e o encaminha a territórios existenciais outros que não o da culpa ou do arrependimento, uma vez que conhece o caminho trilhado como essencialmente necessário e não como contingente. Um dado marcante da origem rural de Juvêncio, frisado várias vezes por ele nas duas entrevistas, era a pobreza lá vivenciada. Dessa forma, o sofrimento de trabalhar muito e não obter recompensas de valor material e simbólico parece encaminhar Juvêncio para um tipo de consciência sobre a vida marcada pelo não arrependimento do trajeto trilhado por ele até o momento.

Eu sofri muito na roça. Eu sofri muito trabalhando para os outros, não consegui nada. Não podia comprar um sapato novo, não podia comprar nada. Me aborreci, entendeu? E lá eu passava fome... Não dão valor no que você faz, entendeu? Mas é bem melhor do que aqui preso, né. Mas... O homem não pode se arrepender do que ele faz. Eu mesmo não posso me arrepender, porque já fiz, já paguei, 'tô pagando e aí? Se eu me arrepender vai dar em que? Não posso é fazer a mesma coisa, entendeu? Mas, me arrepender... Eu só me arrependo de uma coisa só na roça mesmo, de eu não ter tratado bem a minha família lá. Só isso.

Percebam que o se sentir culpado e arrepender-se parece fazer parte do discurso cristalizado no presídio, como ponto de chegada para o cumprimento da pena. Discurso com o qual Juvêncio rompe nas práticas discursivas construídas com a pesquisadora. Para afirmar o não arrependimento, o entrevistado retoma sempre sua vida no interior como uma realidade de precariedades para a qual não deseja voltar, embora não seja pior do que a realidade prisional. Assim como o fez Jésus na primeira entrevista, Juvêncio aponta para o fato de que ninguém deseja para si e para a sua família a vida marcada pelo "sofrimento ético-político" de discriminação, de apêndice inútil da sociedade e de total carência de alimentação e de bens culturalmente produzidos e valorizados socialmente. Desta forma, Juvêncio pontua a atividade criminosa desenvolvida por ele como estratégia de sair desse lugar de exclusão:

Primeiramente era dinheiro, não se pode misturar essa questão, porque eu ganhava dinheiro num dia. Geralmente eu começava de manhã e terminava à noite, era o dia todo, né? E ganhava um bom dinheiro, entendeu? Mas era um bom dinheiro mesmo.

\section{José e a Atividade de Costurar Bolas}

Na segunda entrevista com José chama-nos a atenção, como grande mudança ocorrida com a passagem de um ano, o seu envolvimento com o trabalho de costura de bolas. Tal atividade, desenvolvida por José há alguns meses no IRS, parece ocupar um lugar importante na sua vida naquele momento, uma vez que atravessou toda a segunda conversa que a pesquisadora teve com ele.

José afirma estar menos ansioso, mais tranqüilo em seu dia a dia no presídio em função da atividade de costura de bolas que o faz "distrair a mente". A função do trabalho realizado no presídio como ocupação da mente, ou distração de maus pensamentos e da ansiedade oriunda da vontade de sair da prisão, aparece em quase todas as entrevistas realizadas na primeira fase da pesquisa. Entendendo, a partir de Leontiev (1978), que atividade e consciência são categorias de análise do psiquismo humano que estão intimamente ligadas entre si e ao processo de formação de sujeitos, podemos analisar a idéia de distração da mente como algo que, num certo limite, confere sentido à vida do sujeito. Desta forma, poderíamos afirmar que José dá sentido ao seu cotidiano através da atividade de costurar bolas. O sentido, de alguma forma, pode possibilitar ao sujeito redimensionar o passado e o presente e fazer incursões na vida futura, o que, há um ano atrás, José não fazia com muita propriedade. Além disso, a atividade é remunerada, o que auxilia na proximidade com o trabalho realizado pe- 
las pessoas em geral. Este é um fator importante na construção da autonomia do sujeito.

Ah, eu compro umas coisas pra gente mesmo. Um monte de coisa, jogo bola também, aposta no jogo de bola, mesmo que não jogo aposto no jogo de bola, perde, ganha... Não dá muito não... Mas dá pra ir levando ... O que eu faço hoje, o que faço, eu costuro bola o dia todo. Se eu tivesse escolhido isso antes, eu não estaria preso, antes, tivesse uma profissão antes, porque vigiar carro também é bom, ganha dinheiro também, mas é serviço para vagabundo mesmo. Eu, quando vigiava carro, eu roubava porque, sei lá, sempre aparecia um amigo - Vamos roubar uma parada aí? Vamos. Aí eu saía e ia roubar. Se eu tivesse procurado um emprego de carteira assinada era melhor. Nunca preocupei com assinar carteira, em trabalhar com carteira assinada.

O trabalho circunscreve o modo de vida encarcerada de José que atualiza os valores sociais do trabalho e do emprego com carteira assinada.

Ao evocar sua trajetória de vida até a entrada no IRS, José credita o caminho trilhado ao destino. É interessante notar que José, ao mesmo tempo em que diz ser o culpado por estar preso, afirma que tudo foi obra do destino. Assim, também ao falar do futuro, embora procure pensar positivamente em que todo o planejado vai dar certo, pontua a presença do destino. A partir daí, poderíamos pensar nas condições externas a que estão sujeitas uma dada organização (por exemplo, sujeito José). Certos encontros, enquanto afecções passivas, tendem à atualização na medida em que o ser humano, parte de uma totalidade infinita que o determina a todo o momento, tem necessariamente paixões que nada mais exprimem que o peso do todo sobre as partes (Teixeira, 2007).

Culpado sou eu mesmo porque foi, não vou dizer que eu queria ser esse bandido na vida, mas que foi um momento que aconteceu e foi esse destino. E se tem algum culpado, sou eu mesmo. Não tem outra pessoa para culpar assim. Quando sair, pretendo trabalhar. Eu pretendo, né? Do destino quem sabe é só Deus, mas depende de eu chegar lá fora, igual eu já tenho o emprego garantido para trabalhar, depende das pessoas com que eu vou trabalhar, eu só conheço o dono mesmo, tem outros que eu nem conheço, mas vai dar tudo certo. ... Eu sou mais de pensar positivo, que vai dar certo, tem que dar certo. Agora se não der certo, só Deus também pra segurar, mas pra cadeia com certeza eu não vou voltar, roubar eu não vou voltar, eu vou fazer qualquer outra coisa, mas vida do crime, essa com certeza eu não volto mais. Com certeza eu parei, já sofri o suficiente, já paguei o preço caro. Isso não compensa porque dá cadeia mesmo.

\section{Considerações Finais: a Matriz Sócio- Histórica como Processo de Encarceramento, Contexto Prisional e Construção de Modos de Vida Encarcerada}

Nas entrevistas realizadas, os depoimentos dos internos apresentaram, na medida das possibilidades de cada um, o processo vivido por eles até a chegada ao IRS. A história de vida de cada um se manifesta no discurso, em forma de passado que está ativo no presente: "Aquele passado encontra-se atualizado por meio dos significados inscritos nos tipos de organização espacial, nas práticas discursivas, nas formas de relação, etc., evocando, atuando e contribuindo de um modo criador para configurar o aqui-agora" (Rossetti-Ferreira et al., 2004, p. 27).

$\mathrm{O}$ recordar e o falar do tempo vivido quando se está no presídio produzem formas peculiares de interpretar o presente e especular sobre o futuro. É certo que a articulação do tempo passado e do tempo presente, juntamente com os planos e metas, de alguma forma, dimensionam a perspectiva futura e, dialeticamente, esta última demarca e ressignifica os tempos presente e passado. Porém, para alguns internos do IRS, parece efetivamente faltar perspectiva futura diferente ou diversa do passado e do presente. Numa visão macro de suas vidas o que se percebe é apenas a possibilidade de repetição do mesmo, o eterno retorno ao sistema prisional, ou a morte, o que já não seria o retorno ao mesmo, mas que também não representa futuro.

Do material resultante das entrevistas emergiram circunscritores significativos do processo de encarceramento dos sujeitos. Esses permitiram a percepção de descontinuidades nos percursos de vida traçados pelos participantes da pesquisa. A abordagem teórico-metodológica adotada possibilitou que aspectos da vida social dos sujeitos, aparentemente imutáveis, fossem focalizados e examinados a partir da ótica da produção dos sentidos que rompem com a naturalização de discursos arranjados previamente. Afinal

atribuir ao caráter persistente do envolvimento com o crime uma natureza quase imutável, mais do que produzir conhecimento, é posicioná-lo em conformidade com as continuidades, não do ato infracional em si, mas dos discursos e práticas implicados em sua construção. Discursos carregados por uma herança histórica de identificação e associação de infratores a determinados segmentos sociais (Silva, 2003, p. 32).

A partir do conhecimento da história de internos do IRS e do funcionamento da instituição, seguimos na tentativa de compreender parte do contexto que transforma e constitui os modos de vida dos sujeitos que habitam a penitenciária em questão. 
Apostamos nas diferenças entre presídios e internos do sistema prisional e, por isso, na análise das entrevistas elas constituíram o foco da atenção. Apontar as singularidades dos sujeitos entrevistados a partir da iluminação das suas histórias de vida, de seus sentimentos em relação à experiência da vida prisional e de seus modos de vida revela-nos, também, o contexto particular de constituição e de transformação de tais sujeitos.

No período em que coletamos dados no IRS, percebemos e documentamos em diário de campo um elemento importante na constituição de tal contexto: as diretrizes políticas para o sistema prisional (ou a falta delas). Durante o tempo de aproximadamente um anoe seis meses em que visitamos o IRS na condição de pesquisadores presenciamos a passagem de seis diretores entre interinos e oficiais do cargo. Além disso, funcionários importantes da instituição foram transferidos ou exonerados do cargo durante o tempo em que lá estivemos. Evento marcante ocorrido durante esse período foi o da vistoria realizada pelo Batalhão de Missões Especiais da PM ("tropa de choque") no presídio seguida da transferência de aproximadamente 50 presos, o que representava um quarto dos internos do IRS.

Tais eventos transparecem carências de diretrizes políticas claras. Ao contrário, a impressão óbvia primeira a todos, inclusive aos internos, é que a organização e o funcionamento das prisões caminham de acordo com "forças ocultas", fatidicamente relacionadas com o momento político de cada Governador, ou de cada Secretário de Justiça, ou de cada Secretário de Assuntos Penitenciários, ou mesmo de cada Diretor ou Chefe de Disciplinas.

Fatores, tais como: condição familiar de origem, situação de escolaridade e profissionalização, condição de "pré-delinquiência", família constituída, histórias prisionais vividas antes da chegada ao IRS, em conjunto com o contexto prisional vivenciado durante um ano no IRS, delinearam a matriz sócio-histórica constituinte do processo de produção de modos de vida diferenciados para os quatro internos que participaram das segundas entrevistas.

\section{Notas}

${ }^{1}$ No plano representativo, das idéias, afecção é a imaginação advinda do efeito ou da modificação que sofre um corpo quando da ação sobre ele de outro corpo.

${ }^{2}$ A respeito do assunto, Silva (2003) apresenta a idéia de descontinuidade no envolvimento com o crime a partir de estudo da construção de identidade narrativa de ex-infratores.

${ }^{3}$ Espinosa refere-se a idéias inadequadas como sendo conhecimentos de primeiro gênero, que seja a imaginação produzida pelo efeito do encontro de corpos, as afecções. A razão seria um conhecimento de segundo gênero que produziria idéias adequadas por advir do conhecimento das causas. Porém, é preciso afirmar que na leitura de Espinosa não há idéias erradas ou falsas, dadas as possibilidades dos sujeitos compreenderem os fenômenos: "Nada existe de positivo nas idéias que permita chamar-lhes falsas" (Livro 2, Proposição XXXIII, Espinosa, 1992).

${ }^{4}$ Volições determinadas por idéias inadequadas, por afecções passivas.

${ }^{5}$ Poder, característico dos modos de funcionamento do sistema capitalista, exercido através de uma tecnologia de dupla face: disciplinar, que se dirige ao homem-corpo, e biopolítico, que mobiliza a gestão da vida dirigindo-se à população como um todo, ao homem-espécie. O biopoder operacionaliza uma incidência que se caracteriza por uma organização rizomática e por uma ação disseminada nos mais ínfimos detalhes da vida, revestindo-a de ponta a ponta e regulamentando um direito que deverá fazer viver ou deixar morrer (Foucault, 2002)

\section{Referências Bibliográficas}

Chauí, M. (2006). Baruch Espinosa: uma subversão filosófica: o homem e a liberdade. Dossiê Cult. CULT, ano 9, 109, 50-57.

Debord, G. (1997). A sociedade do espetáculo. Rio de Janeiro: Contraponto.

Espinosa, B. (1973). Coleção Os Pensadores. São Paulo: Abril Cultural.

Espinosa, B. (1992). Ética. Lisboa: Relógio D’Água.

Foucault, M. (2002). Em defesa da sociedade. São Paulo: Martins Fontes.

Gleizer, M. A. (2005). Espinosa e a afetividade humana. Rio de Janeiro: Jorge Zahar.

Leontiev, A. N. (1978). Actividad, conciencia y personalidad. Buenos Aires: Ciências del Hombre.

Rossetti-Ferreira, M. C., Amorim, K. S., Silva, A. P. S., \& Carvalho, A. M. A. (Orgs.). (2004). Rede de significações e o estudo do desenvolvimento humano. Porto Alegre: Artmed.

Sampson, E. E. (1993). Celebrating the other: A dialogic account of human nature. New York: Harvester Wheatsheaf.

Segato, R. (2001). Religião, vida carcerária e direitos humanos. In R. Novaes (Org.), Direitos humanos: temas e perspectivas (pp. 137-145). Rio de Janeiro: ABA/Mauad/Ford.

Silva, A. P. S. (2003). (Des) continuidade no envolvimento com o crime: construção de identidade narrativa de ex-infratores. São Paulo: IBCCRIM.

Spink, M. J. \& Frezza, R. M. (2004). Práticas discursivas e produção de sentidos: a perspectiva da psicologia social. In M. J. Spink (Org.), Práticas discursivas e produção de sentidos no cotidiano: aproximações teóricas e metodológicas. (pp. 1739) São Paulo: Cortez.

Spink, M. J. \& Medrado, B. (2004). Produção de sentidos no cotidiano: uma abordagem teórico-metodológica para análise das práticas discursivas. In M. J. Spink (Org.), Práticas discursivas e produção de sentidos no cotidiano: aproximações teóricas e metodológicas. (pp. 41-61) São Paulo: Cortez.

Spink, M. J. \& Menegon, V. M. (2004). A pesquisa como prática discursiva: superando os horrores metodológicos. In M. J. Spink (Org.), Práticas discursivas e produção de sentidos no cotidiano: aproximações teóricas e metodológicas. (pp. 63-92) São Paulo: Cortez. 
Teixeira, R. (2007). Ética: tratado do corpo sem órgãos. Manuscrito não-publicado.

Thompson, A. F. G. (1976). A questão penitenciária. Petrópolis, RJ: Vozes.

Vygotsky, L. S. (1991). A formação social da mente. São Paulo: Martins Fontes.

Gilead Marchezi Tavares é Doutora em Psicologia pela UFES. Professora do Departamento de Psicologia e do Programa de Pós-Graduação em Psicologia Institucional da UFES. Endereço para correspondência: UFES Centro de Ciências Humanas e Naturais. Av. Fernando Ferrari. Goiabeiras. Vitória - ES, Brasil. Cep 29000-000

E-mail: gilead.dindin@ig.com.br

Paulo Rogério Meira Menandro é Doutor em Psicologia. Professor do Departamento de Psicologia Social e do Desenvolvimento e do Programa de PósGraduação em Psicologia da UFES.

E-mail: paulomenandro@uol.com.br

Modos de vida de internos do sistema penitenciário capixaba

Gilead Marchezi Tavares e Paulo Rogério Meira Menandro Recebido: 26/02/2008

Aceite: 29/06/2008 